\title{
Analysis of the temperature distribution in the pin bundle of the CIRCE facility
}

F. Buzzi, A. Pucciarelli, F. Galleni, M. Tarantino, N. Forgione

\section{Abstract}

In this paper, a CFD analysis of the Fuel Pin Simulator (FPS) of the CIRCE-HERO facility built at the ENEA research centre in Brasimone was performed. STAR-CCM+ code was used with the purpose of reproducing steady-state and transient experimental conditions adopting LBE as working fluid. RANS and URANS simulations were performed comparing the calculated temperature trends with the experimental data. In particular, the FPS average outlet temperature was monitored for the transient case and an exhaustive study of the heat transfer between the FPS and the pool during the transient was carried out. The impact of the involved heat transfer phenomena on the FPS energy balance was studied from a quantitative point of view and the relevant difference in terms of thermal inertia between pool and FPS component was pointed out.

Keywords: CFD; Liquid Metals; Thermal-Hydraulics 


\section{Introduction}

Liquid metals are envisaged to be the operational coolant of two typologies of nuclear reactors in the frame of the Generation IV International Forum (GIF): the Lead-cooled Fast Reactor (LFR) and the Sodium-cooled Fast Reactor (SFR). Using liquid metals as primary fluid in a nuclear power plant grants several advantages: the possibility to adopt a fast neutron spectrum inside the core, the capability to rely on natural convection both in operating and accidental conditions, a very high boiling temperature strongly limiting the dry out risk, a relatively high thermodynamic cycle efficiency and a lower operating pressure. On the other hand, such a technology also requires dealing with challenging aspects such as the high melting temperature, the fluid opacity and the necessity to avoid possible chemical interactions with water and air (especially for sodium).

During the last years, several experimental campaigns and numerical studies aiming at improving the present knowledge on liquid metals thermal-hydraulics were carried out in support of the development of Heavy Liquid Metal Reactors (HLMFRs). Many experimental facilities were designed, as e.g. E-SCAPE (Abderrahim, 2011), NACIE-UP (Di Piazza et al., 2013), CIRCE-ICE (Tarantino et al., 2011), TALL-3D (Grishchenko et al., 2015), CIRCE-HERO (Pesetti et al., 2018a), in order to provide relevant information for the development of correlations and CFD analyses.

More specifically, studies of liquid metals flow conditions in a pool-type facility were carried out by Toti et al. (2018) for the ESCAPE facility and by Papukchiev et al. (2015) for the TALL 3D facility; in recent years many experimental campaigns were performed at the ENEA research centre in Brasimone (see e.g. Lorusso et al., 2018 Lorusso et al., 2019) providing material for several numerical studies (Martelli et al., 2014, Angelucci et al., 2017a, Narcisi et al., 2017, Martelli et al., 2017a, Martelli et al., 2017b, Gonfiotti et al., 2018, Forgione et al., 2019, Zwijsen et al. 2019a, Zwijsen et al., 2019b). A detailed overview of the experimental and numerical works recently performed in support to the design of HLMRs is reported in the paper of Roelofs et al. (2013).

In literature several examples of CFD simulations of the thermal-hydraulics phenomena occurring in rod bundles of HLMRs are available (Groetzbach, 2003, Cheng and Tak, 2005, Chandra et al., 2009, Chandra and Roelofs, 2011, Shams et al., 2014, Shams et al., 2019, Pucciarelli et al., 2020), discussing both the capabilities and the drawbacks of the CFD approach. Particular attention was paid to the analysis of the turbulent heat flux phenomenon, pointing out the need for different definitions of the turbulent Prandtl number and suggesting the need for advanced correlations (see e.g. Shams et al., 2019).

This work is dedicated to the phenomena occurring inside the Fuel Pin Simulator (FPS) component of the CIRCE-HERO facility (Pesetti et al., 2018a). The code STAR-CCM+ (Siemens, 2019) was used with the aim of comparing CFD results and experimental data for the steady and transient cases (Lorusso et al., 2018 and Lorusso et al., 2019). In particular, the temperature distributions inside the fuel pin simulator of the CIRCE-HERO facility were analysed. In addition, the information gained in previous work (Buzzi et al., 2020) regarding the heat transfer between pool and FPS was taken into account. Indeed, in the present paper, the impact of different imposed thermal boundary conditions on the FPS fluid temperature distribution was evaluated, underlining relevant differences between 
the steady and transient conditions. A good matching between numerical and experimental results was obtained and the CFD approach made possible to clarify some interesting physical phenomena.

\section{CIRCE-HERO experimental facility}

The LBE pool CIRCE (CIRColazione Eutettico) is a multipurpose facility built at ENEA CR Brasimone with the purpose of investigating heat transfer phenomena in large pool involving liquid metals in support of the development of the HLM Generation IV nuclear reactors.

The CIRCE's main vessel consists in a $1200 \mathrm{~mm}$ diameter and $8500 \mathrm{~mm}$ height vessel partially filled with about 70 tonnes of Lead-Bismuth Eutectic (LBE); argon is used as cover gas. The test section is located inside the CIRCE main vessel and it consists of several components: the Fuel Pin Simulator (FPS), the Fitting Volume (FV), the riser, the separator and the Steam Generator Bayonet Tube (SGBT), named HERO "Heavy liquid mEtal-pRessurised water cOoled tube". In Figure 1 a sketch of the CIRCE-HERO facility is reported. The LBE enters from the pool downcomer in the test section loop and it is firstly heated in the FPS. Afterwards, the LBE is collected in the FV and moves to the riser, in which the upward flow is enhanced by the injection of argon (i.e. gas-lift). The LBE is subsequently collected in the separator and later moves to the SGBT, which is accountable for the heat removal, and returns to the pool. In analysing the data, it is also important to consider that the FPS and FV are not thermally insulated; therefore, heat transfer from and towards the pool is allowed (Pesetti et al, 2018b).

In the present paper, the FPS is the main component under investigation; a detailed description of its internals is thus reported. The FPS consists of a bundle composed by 37 electrically heated pins with a total nominal thermal power of about $1 \mathrm{MW}$. The pins are arranged inside a hexagonal wrapper, forming a hexagonal lattice with a pitch to diameter ratio of 1.8 (see Figure 2a). The outer diameter of the electrical pins is $8.2 \mathrm{~mm}$ and the total axial length of the pins is $1885 \mathrm{~mm}$. Each pin may supply a thermal power of about $25 \mathrm{~kW}$ by Joule effect, which is provided by two electrical nickel-chrome wires arranged inside an inox pipe (Figure $2 \mathrm{~b}$ ). Three spacer grids (Figure $2 \mathrm{c}$ ) are placed along the FPS in order to assure a correct positioning of the heating rods. The rods active length is $1000 \mathrm{~mm}$ and it is in the centre of the FPS component; the initial $350 \mathrm{~mm}$ and 535 final mm unheated regions are used as mixing zones. Figure $2 \mathrm{~d}$ shows a sketch of the FPS also reporting the location of the spacer grids: two are located immediately below and above the heated region and one is instead allocated right in the middle of the active length. The instrumentation installed in the test section is composed by an overall number of about 170 thermocouples. Inside the FPS are located 39 thermocouples (see Figure 2e): 7 close to the lower spacer grid, 16 in the region of the middle spacer grid, 13 in the vicinity of the upper spacer grid and 3 placed at the FPS exit slot. The LBE mass flow rate is measured at the inlet of the FPS by mean of a Venturi flow meter.

The experimental data considered in this work were collected in recent experimental campaigns (Lorusso et al., 2018; Lorusso et al., 2019) performed at the ENEA CR Brasimone; both steady-state and transient experimental conditions were considered. Table 1 reports the operating conditions of the experimental cases which were selected for the present CFD analyses. 


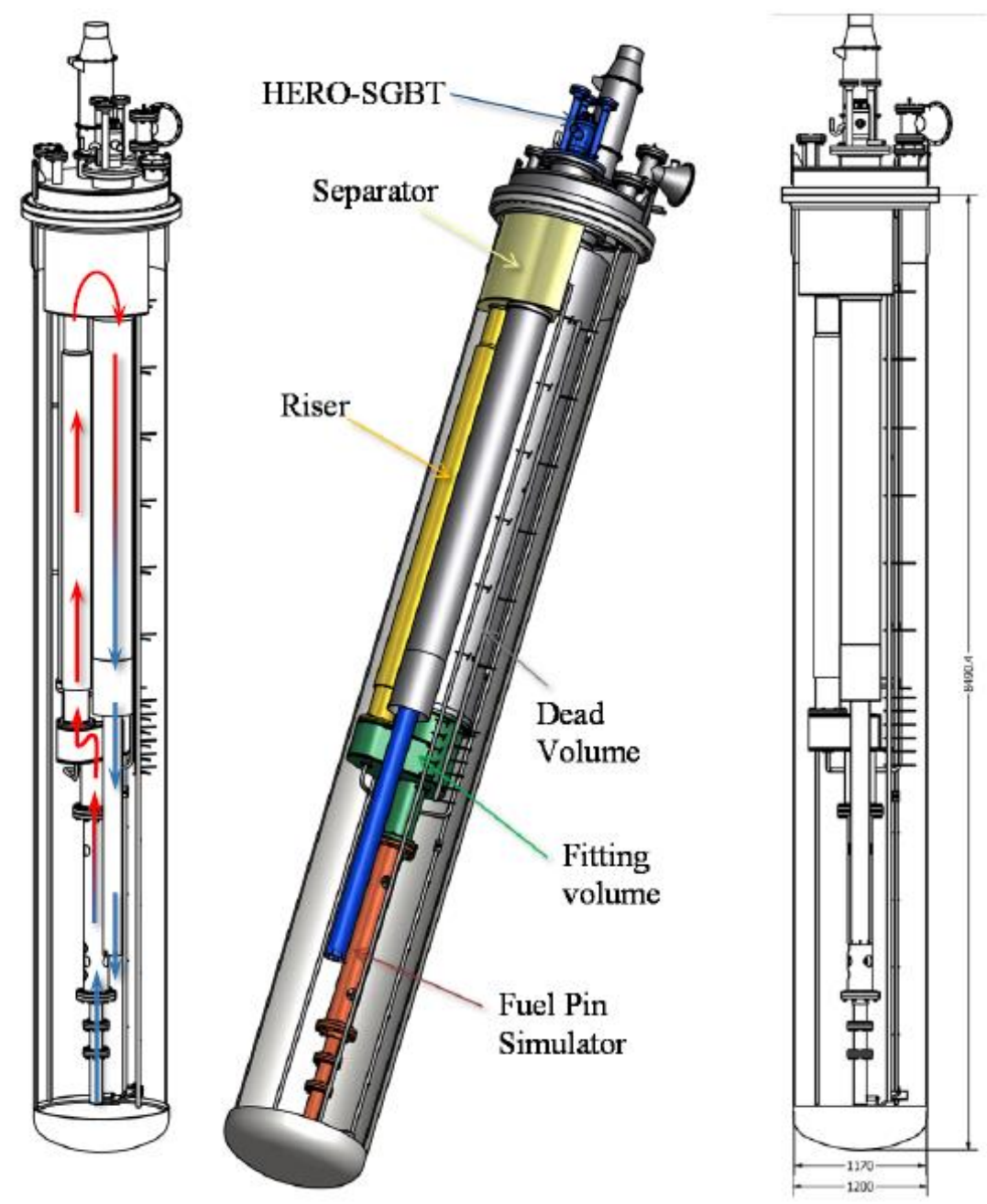

Figure 1: CIRCE-HERO facility (Pesetti et al., 2018) 


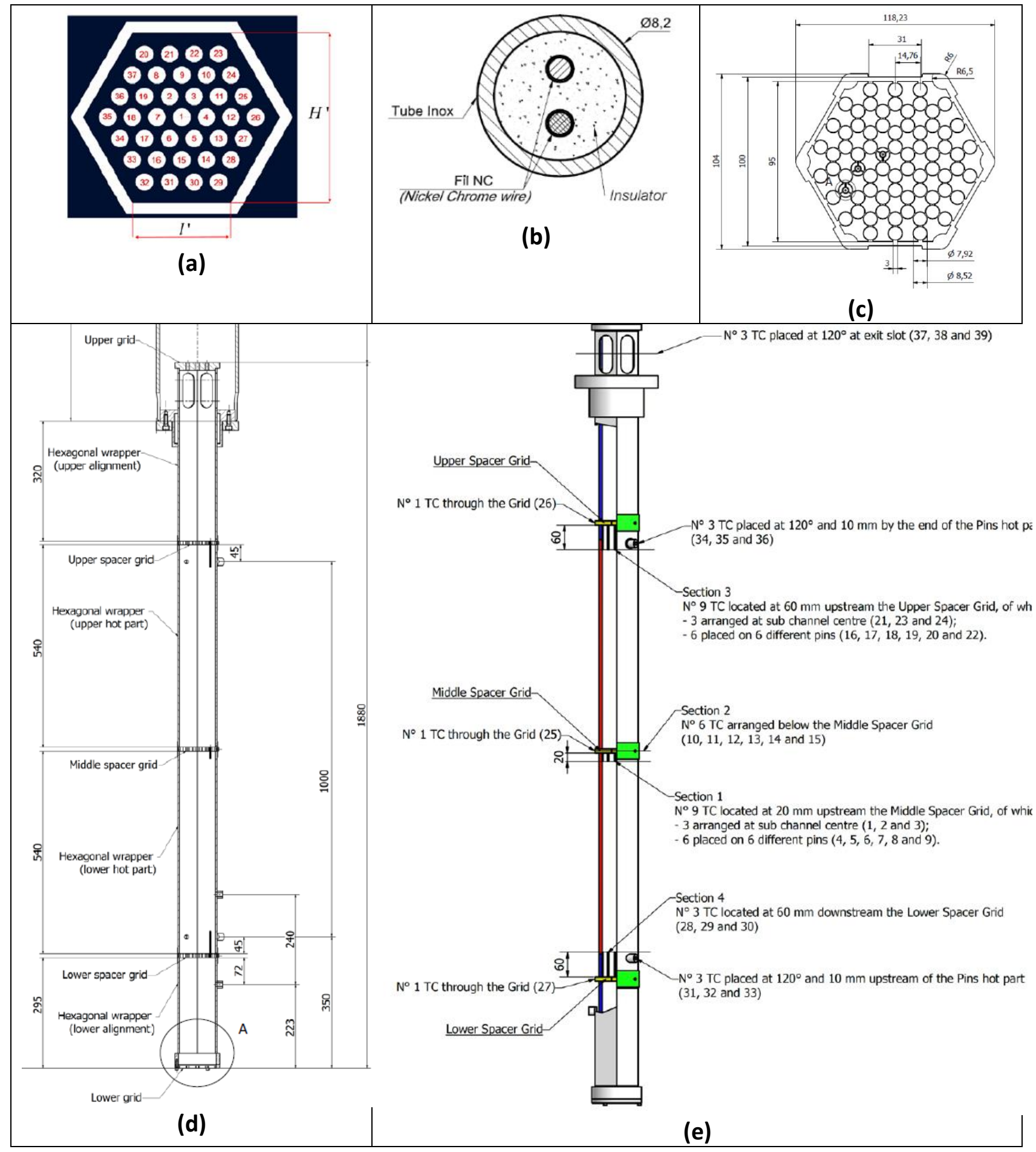

Figure 2: (a) Hexagonal wrapper characteristics and pins position, (b) pin internal structure, (c) spacer grid design, (d) geometrical configuration and (e) thermocouples positions along the FPS component (Pesetti et al., 2018) 
Steady-state cases

\begin{tabular}{|c|c|c|c|c|}
\hline & $\dot{\mathrm{m}}[\mathrm{kg} / \mathrm{s}]$ & \multicolumn{2}{|c|}{ Power [kW] } & \multicolumn{2}{c|}{$T_{\text {in }}\left[{ }^{\circ} \mathrm{C}\right]$} \\
\hline Test Reference & 30 & \multicolumn{2}{|c|}{90} & 221 \\
\hline Test 1 & 31 & \multicolumn{2}{|c|}{140} & 231 \\
\hline Test 2 & 29 & \multicolumn{2}{|c|}{27} & \multicolumn{2}{c|}{207} \\
\hline Test 3 & 39 & \multicolumn{2}{|c|}{ Transient case } \\
\hline
\end{tabular}

Table 1: FPS operating conditions considered in the present paper

\section{Computational domain and turbulence models}

The main aim of the present work is reproducing some of the physical phenomena occurring inside the FPS component of the CIRCE-HERO facility by using the CFD approach. In particular, for the addressed steady-state cases, the purpose is to compare the calculated and experimental axial and radial temperature distributions inside the FPS component while, for the transient case, the main objective is to analyse the time trend of the outlet FPS temperature. Therefore, a geometrical domain representing only the FPS component was designed. Furthermore, in order to reduce the computational efforts, only one twelfth of the FPS configuration was simulated taking advantage of the hexagonal symmetry; the simulated axial length was $1440 \mathrm{~mm}$, slightly reducing the inlet and outlet mixing zones. Mass flow inlet and pressure outlet boundary conditions were set at the inlet and outlet FPS sections respectively; a wall with no-slip conditions was instead imposed at the external shroud. Several sensitivity analyses regarding the thermal specification to be imposed at the external shroud of the FPS were performed, considering adiabatic, convective or imposed temperature conditions. Symmetry boundary conditions were imposed on the lateral surfaces. In order to reduce the total cell count, the internal part of the pins, i.e. the insulator together with the double electrical wire, were not simulated. Consequently, in the numerical model the heat is not generated in the electric wire, but an imposed heat flux condition is accordingly set on the inner wall of the pins walls. Figure 3 shows a representation of the described CFD domain, also specifying the imposed boundary conditions.

All the RANS and URANS simulations reported in this paper were performed adopting the commercial CFD code STAR-CCM+13.06.011 (Siemens, 2019). The mesh was realised adopting a polyhedral nodalization together with a base size cell value of $1 \mathrm{~mm}$. A mesh refinement was 
performed in the proximity of the three spacer grids in order to obtain improved prediction of the involved phenomena. As a consequence, six prism layers together with a prism layer thickness of $0.3 \mathrm{~mm}$ and a prism layer stretching of 1.5 were set in that region. The obtained mesh counts a total of about $3 \cdot 10^{6}$ cells. The so obtained wall $y^{+}$values are mostly in the order of the unity; nevertheless, in the vicinity of the grids, a maximum value of about 4 is sometimes reached because of the increase in the velocity due to the reduction of the available flow section. Consequently, an "All $y^{+}$ wall-treatment" was considered, since it allows the code to adapt the wall-treatment method depending on the calculated local wall $y^{+}$value (Siemens, 2019). Figure 4 reports a plane section of the obtained nodalization in correspondence of the grid zone.

One of the most relevant open issue in the simulation of heat transfer to liquid metals is the selection of a suitable method for the turbulent heat flux modelling (Shams et al. 2019). In fact, the molecular Prandtl number of liquid metals is usually lower than unity (in the order of 0.01) and therefore they may not be suitable for the assumptions considered by the Reynolds analogy. Shams et al. (2019) suggested that algebraic heat flux models shall be used for a better representation of the turbulent heat fluxes; however, in literature, the most widely adopted technique still relies on the definition of a not unitary turbulent Prandtl number. This assumption proved to be sufficiently reliable yet allowing the use of simplified simulation techniques. In this work a $\mathrm{Pr}_{t}$ of 1.5 was set in accordance with the other previous CFD studies on heat transfer in liquid metals (e.g. Martelli et al, 2017 and Buzzi et al., 2020) where a $\mathrm{Pr}_{\mathrm{t}}$ in a range of $1<\mathrm{Pr}_{\mathrm{t}}<3$ was considered.

In agreement with the work performed in the previous study of Buzzi et al., 2020, the calculations were performed adopting a largely used turbulence model: the SST k- $\omega$ turbulence model (Menter, 1994). The unsteady simulations were performed using a $1^{\text {st }}$-order implicit scheme.

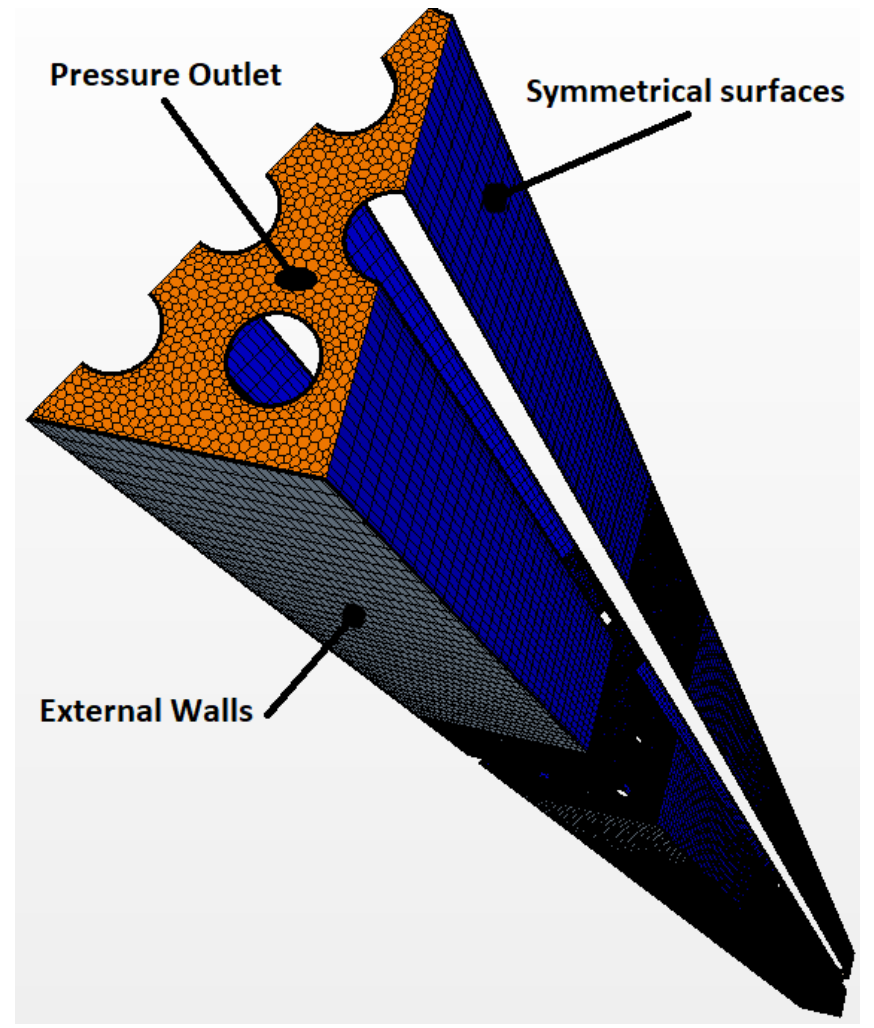

(a)

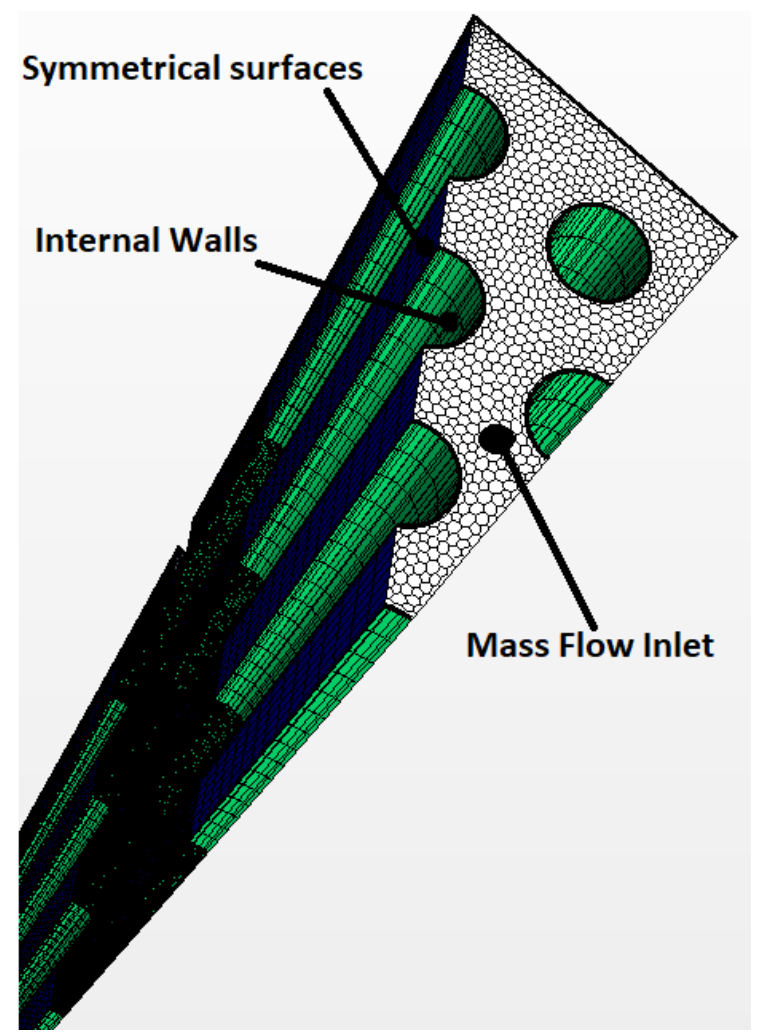

(b) 
Figure 3: Mesh and boundary conditions at the top (a) and at the bottom (b) of the computational domain

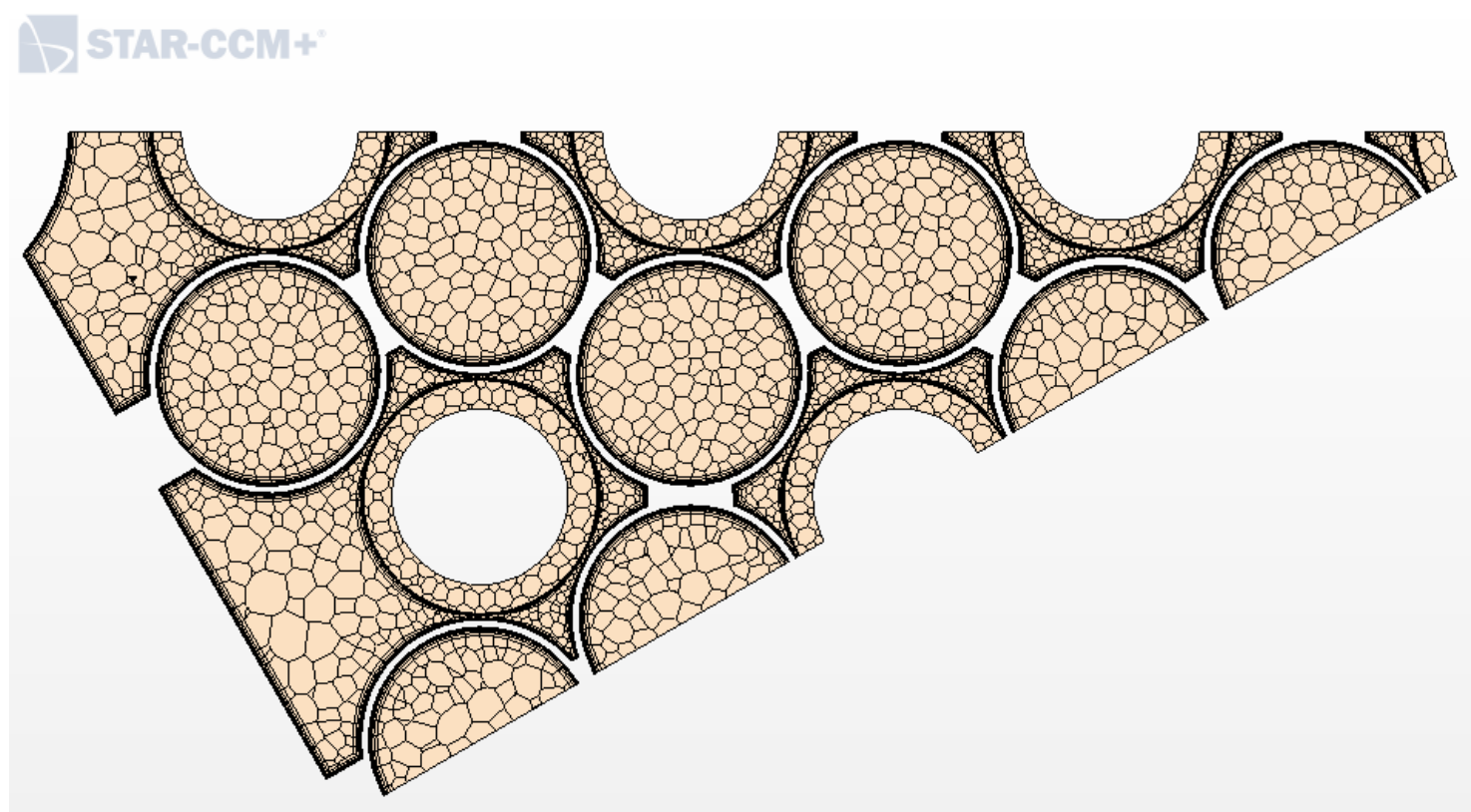

Figure 4: Radial section of the mesh in the middle spacer grid axial position obtained with STAR$\mathrm{CCM}+$

\section{Results}

\subsection{Steady-state cases}

In this section a comparison between numerical and experimental results for the addressed steadystate cases is reported. In particular, Figure 5 reports a representation of the CFD domain showing the positions of the thermocouples located inside the FPS; the orange surface is the fluid region and the grey surfaces are the solid pins. Five thermocouples are directly into contact with the pins walls and here were named P1, P7, P17, P18 and P34 (e.g. P1 is in contact with Pin number 1); three thermocouples are instead placed in the bulk regions far from the walls and here were named $B 1$, B2 and B3. The calculated CFD axial temperature trends were compared with the available experimental measurements collected at three distinct axial locations.

\subsubsection{Sensitivity analyses on the imposed thermal boundary conditions}

As anticipated in Section 2, the FPS component is not insulated and heat transfer with the pool consequently occurs. Four simulations with different thermal boundary conditions imposed at the FPS external walls were performed for the reference case in order to assess the best predicting capabilities. The imposed conditions are adiabatic condition (no heat exchange with the pool) and convective conditions adopting three different heat transfer coefficients, 1000, 2000 and 5000 $\mathrm{W} /\left(\mathrm{m}^{2} \mathrm{~K}\right)$ in similarity with the previous work Buzzi et al. (2020). For the cases in which a convective condition was considered, the environmental temperature was set in accordance with the 
measured pool axial temperature. During this preliminary phase, the only bulk positions B1, B2 and B3 were considered for the comparison, since negligible effects were observed for the axial temperature trends in proximity of the pins (P1, P7, etc.). Figure 6 shows the results related to the Test Reference case: only the adiabatic case and the one assuming a convective heat transfer coefficient of $5000 \mathrm{~W} /\left(\mathrm{m}^{2} \mathrm{~K}\right)$ are reported in order to improve the readability. It can be noted that CFD trends are in good agreement with the experimental data and that negligible differences occur when considering different boundary conditions.

Figure 7 reports the temperature contour plots at the outlet section for the adiabatic case and the one assuming a convective coefficient of $5000 \mathrm{~W} /\left(\mathrm{m}^{2} \mathrm{~K}\right)$; it can be easily noted that no significant discrepancies appear except for a small region (with a difference of about $2^{\circ} \mathrm{C}$ ) near the wall. As a final remark for this section, it can be pointed out that the heat transfer with the pool does not impact relevantly on the temperature fields inside the FPS component. In fact, the total heat flux exchanged between the FPS and the pool in the best situation (i.e. heat transfer coefficient of 5000 $\mathrm{W} /\left(\mathrm{m}^{2} \mathrm{~K}\right)$ ) is about $180 \mathrm{~W}$, which is negligible when compared to the heat supplied by the heating rods (about $0.2 \%$ ). Consequently, for the sake of simplicity, an adiabatic thermal boundary condition was assumed for all the subsequent steady-state simulations.

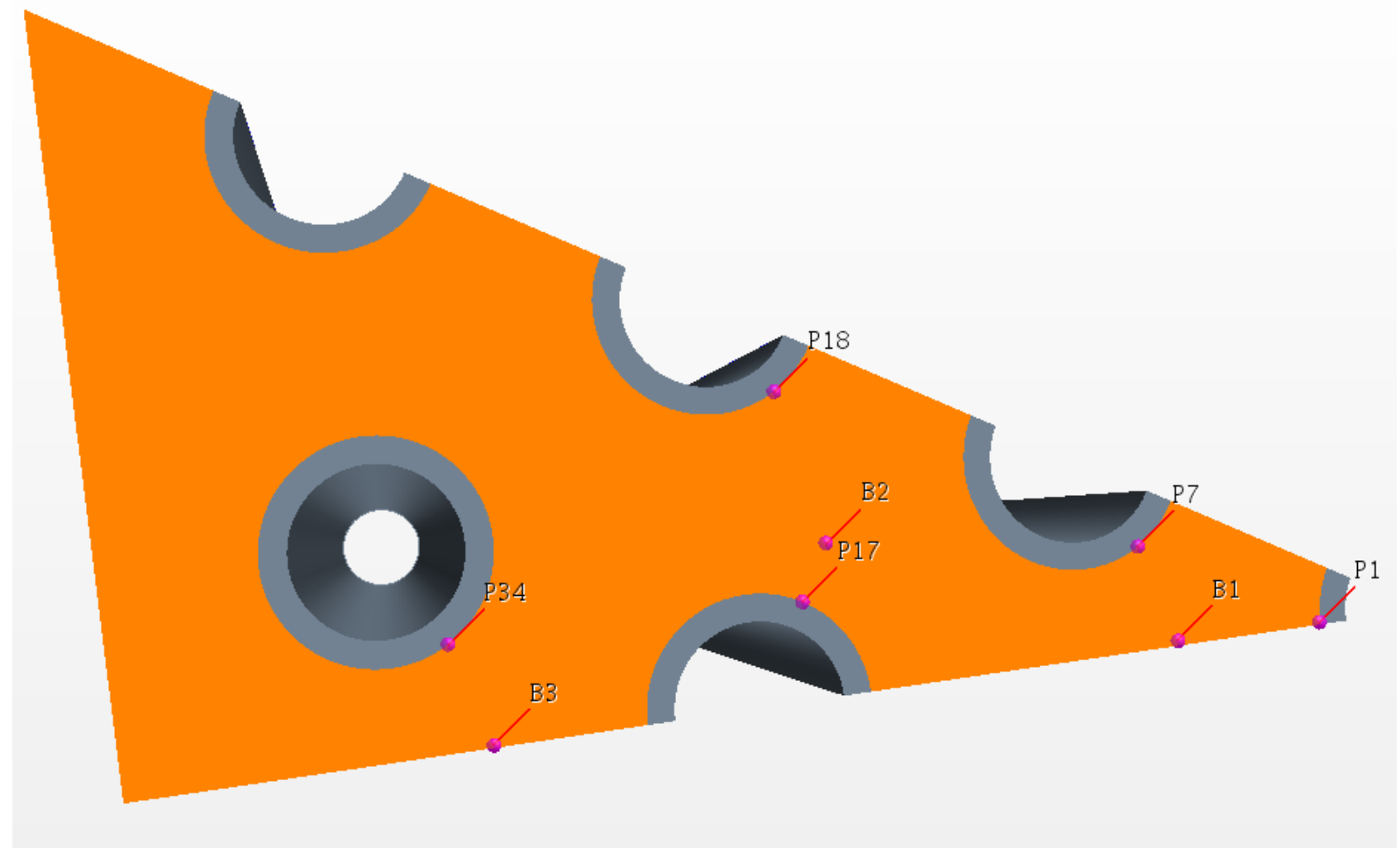

Figure 5: Axial temperature positions in the CFD domain: fluid region is orange and pin regions are grey 


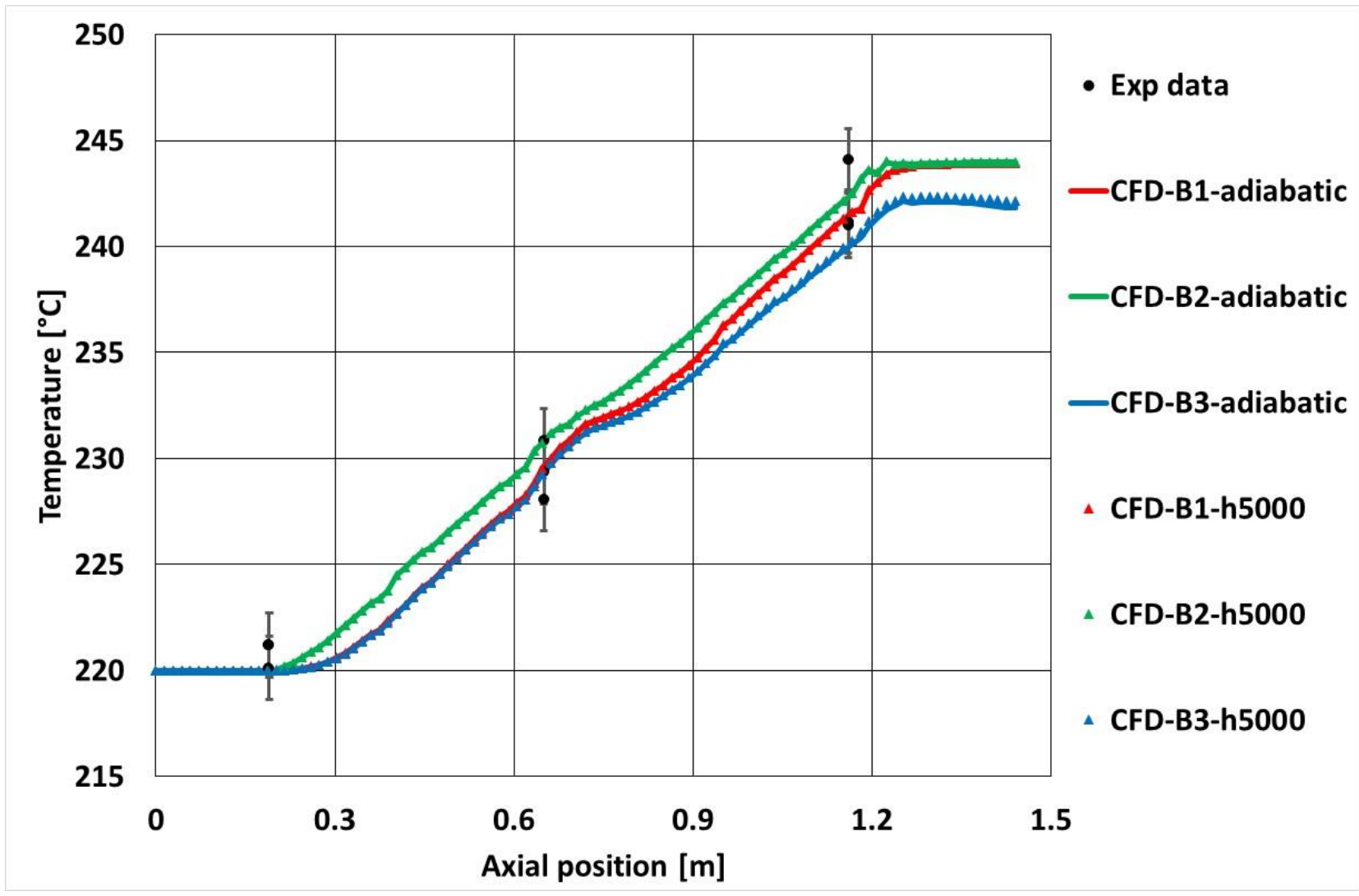

Figure 6: Thermal boundary conditions comparison for the Test Reference case

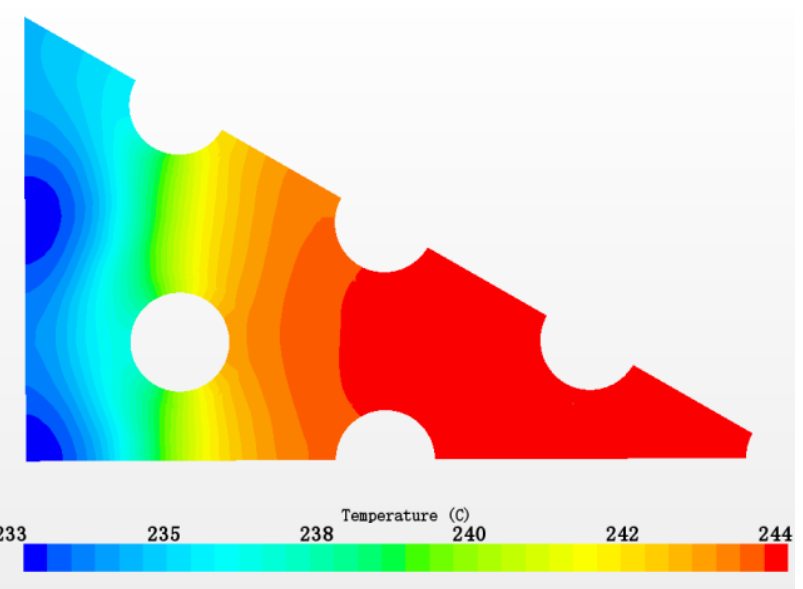

(a)

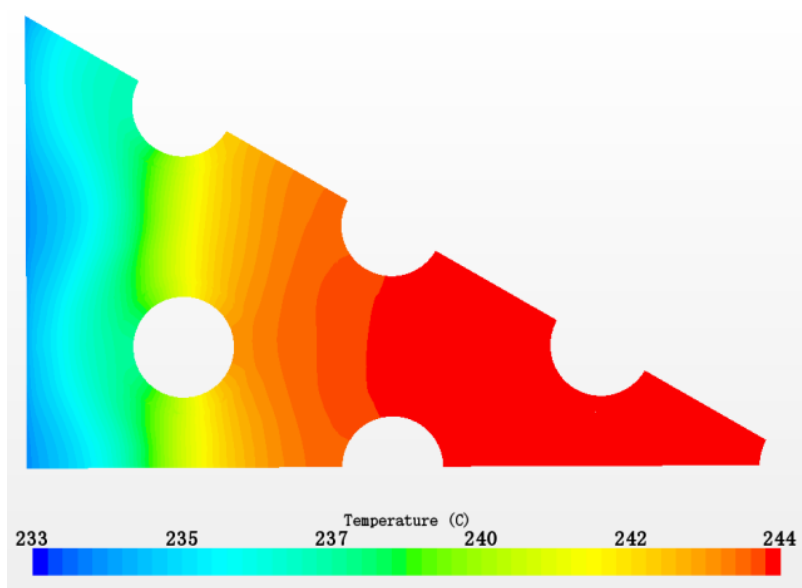

(b)

Figure 7: Radial temperature distributions for the Test Reference case with (a) an adiabatic and (b) a $\mathrm{h}=5000 \mathrm{~W} /\left(\mathrm{m}^{2} \mathrm{~K}\right)$ convective thermal boundary condition

\subsubsection{Steady-state analysis}

In this section, the results obtained for the four addressed steady-state cases were reported and compared with the experimental data in Figure 8. It can be noted that for the B1, B2 and B3 positions the numerical trends are in good agreement with the experimental measurements except for small discrepancies observed in proximity of the middle spacer grid. In fact, in this region, CFD codes tend 
to slightly overestimate the measured temperature values especially for Test 1 and Test 2 cases; nevertheless, the temperature differences are in the order of $2-3^{\circ} \mathrm{C}$ and consequently can be considered negligible, also considering the thermocouples measurement uncertainty $\left( \pm 1.5^{\circ} \mathrm{C}\right.$, see Lorusso et al., 2018).

In proximity of the pins (see Figure $8 b, 8 d, 8 f$ and $8 \mathrm{~h}$ ), a little peak in the temperature value in correspondence of the middle spacer grid can be observed in both the numerical and the experimental results; CFD may help in understanding the possible causes of this phenomenon. This localized temperature increase is likely due to the effects generated on the fluid flow by the gridpins interaction since, as can be seen in Figure 9, it exactly occurs in correspondence of the spacer grid region. In this region, the fluid flow section is reduced by the presence of the grid and, especially in correspondence of the pins walls, it becomes extremely narrow. This configuration dramatically increases the pressure drops and reduces the local mass flux in the vicinity of the pin wall; in the bulk region, instead, the fluid axial velocity increases relevantly. The interaction of these fluid streams, together with the wake effect of the grid itself, leads to the generation of a stagnation zone in the region immediately downstream the grid as reported in Figure 10. As a consequence, turbulence really impairs thus making conduction the dominating heat transfer mechanism in this region; the heat transfer capabilities consequently locally decrease leading to the observed temperature increase.

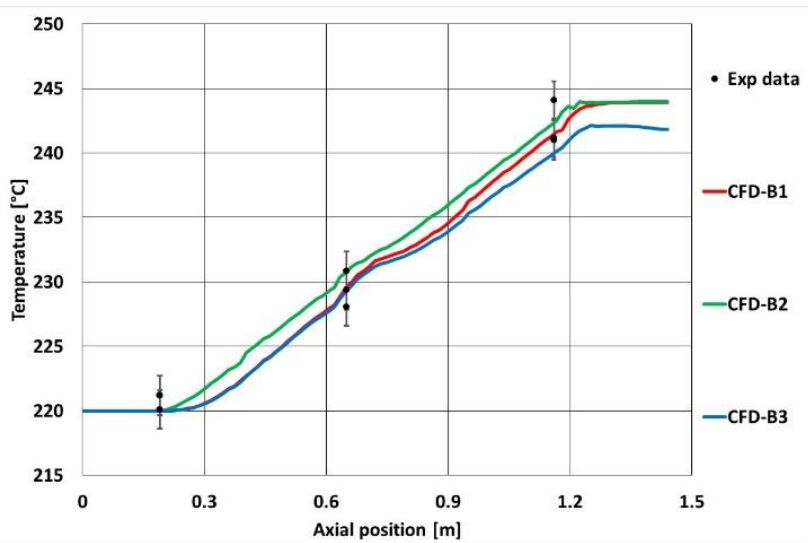

(a)

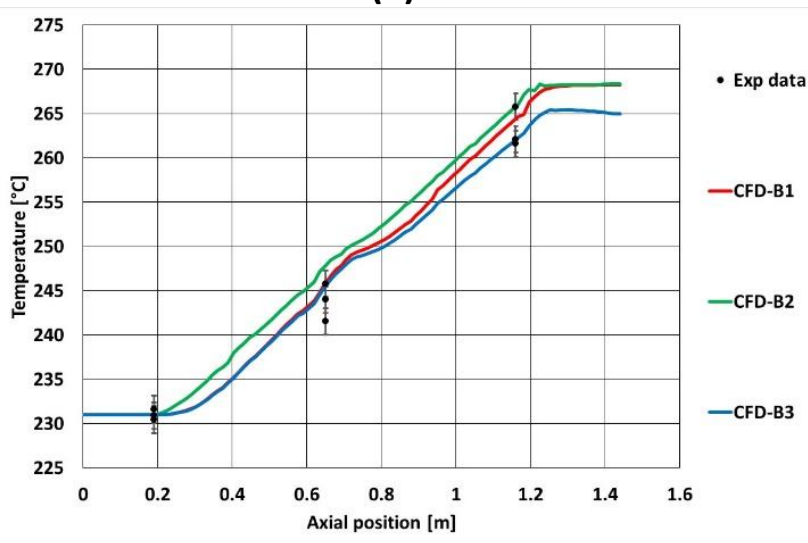

(c)

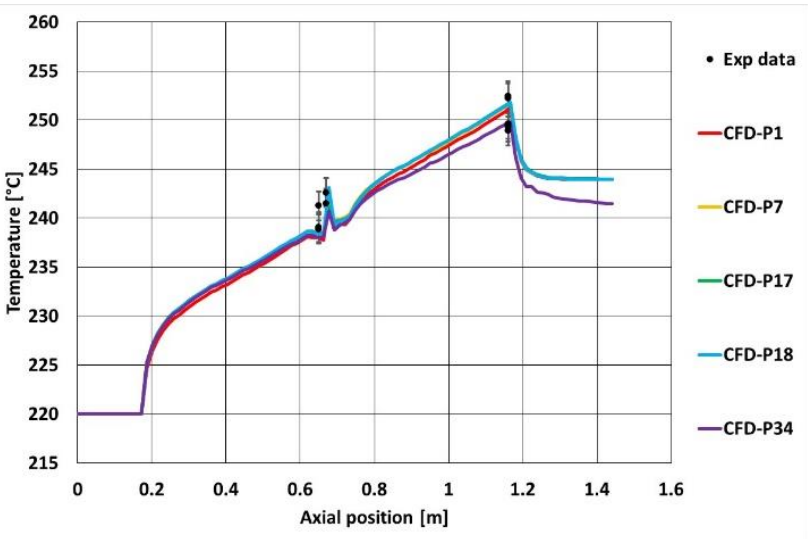

(b)

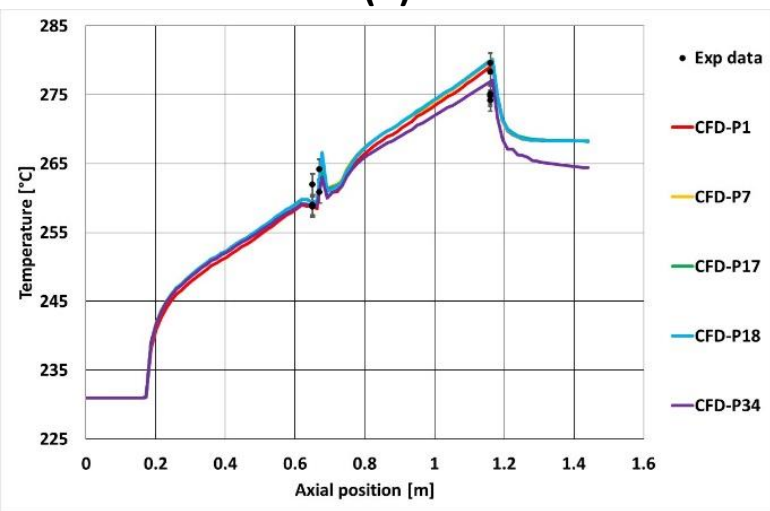

(d) 


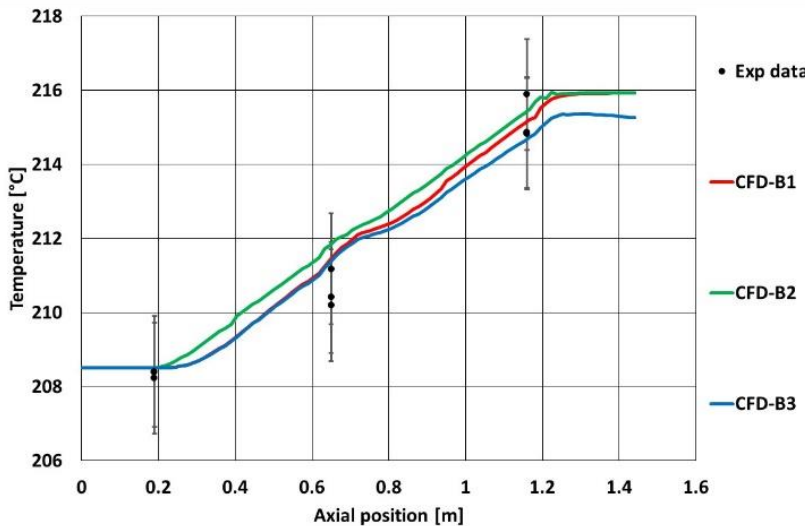

(e)

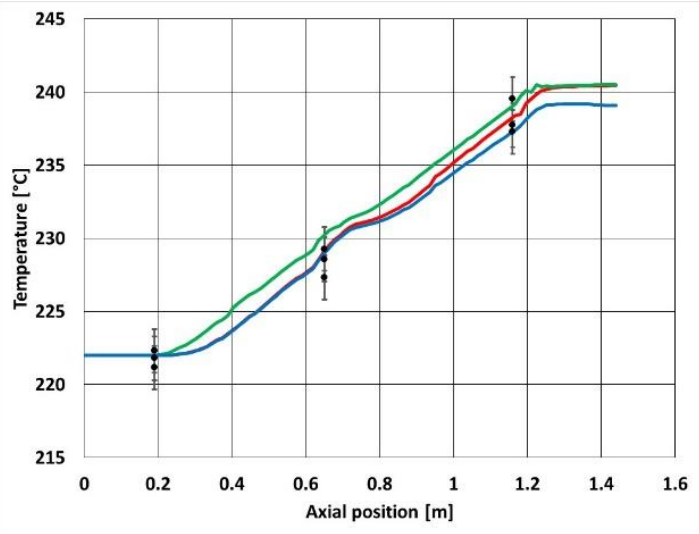

(g)

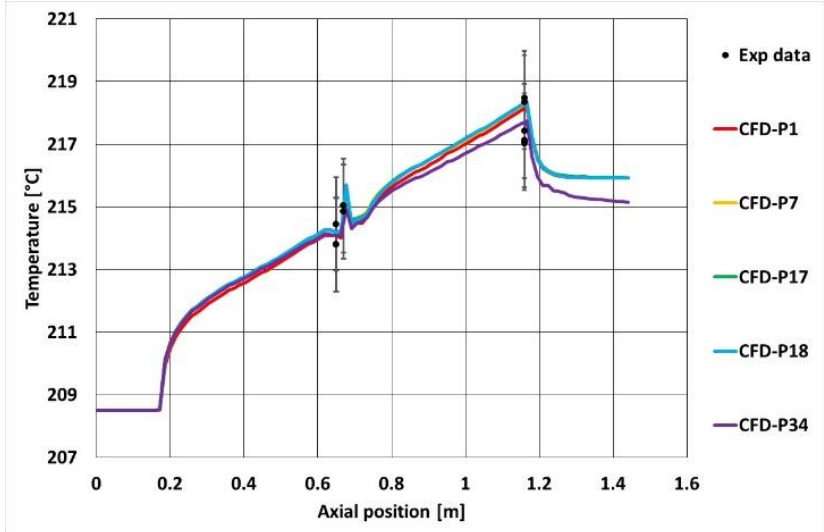

(f)

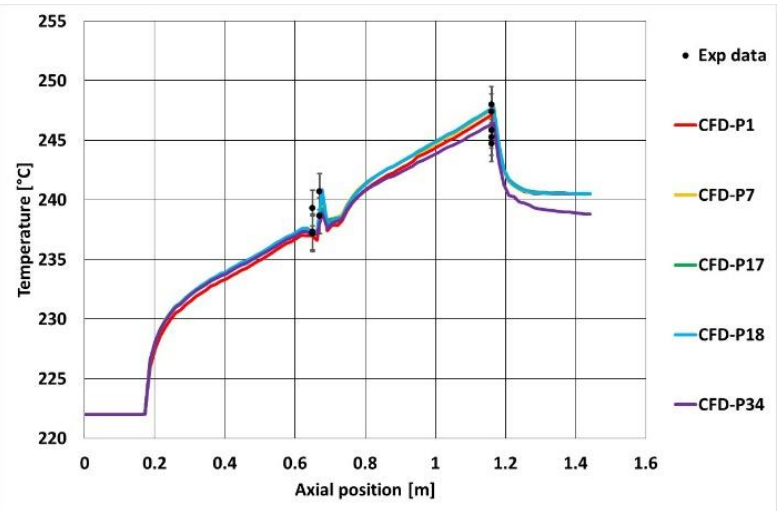

(h)

Figure 8:STAR-CCM+ and experimental results of the axial temperature trends for the "bulk" and "pins-wall" positions for the (a),(b) Test Reference, (c),(d) Test 1, (e),(f) Test 2 and (g),(h) Test3 cases

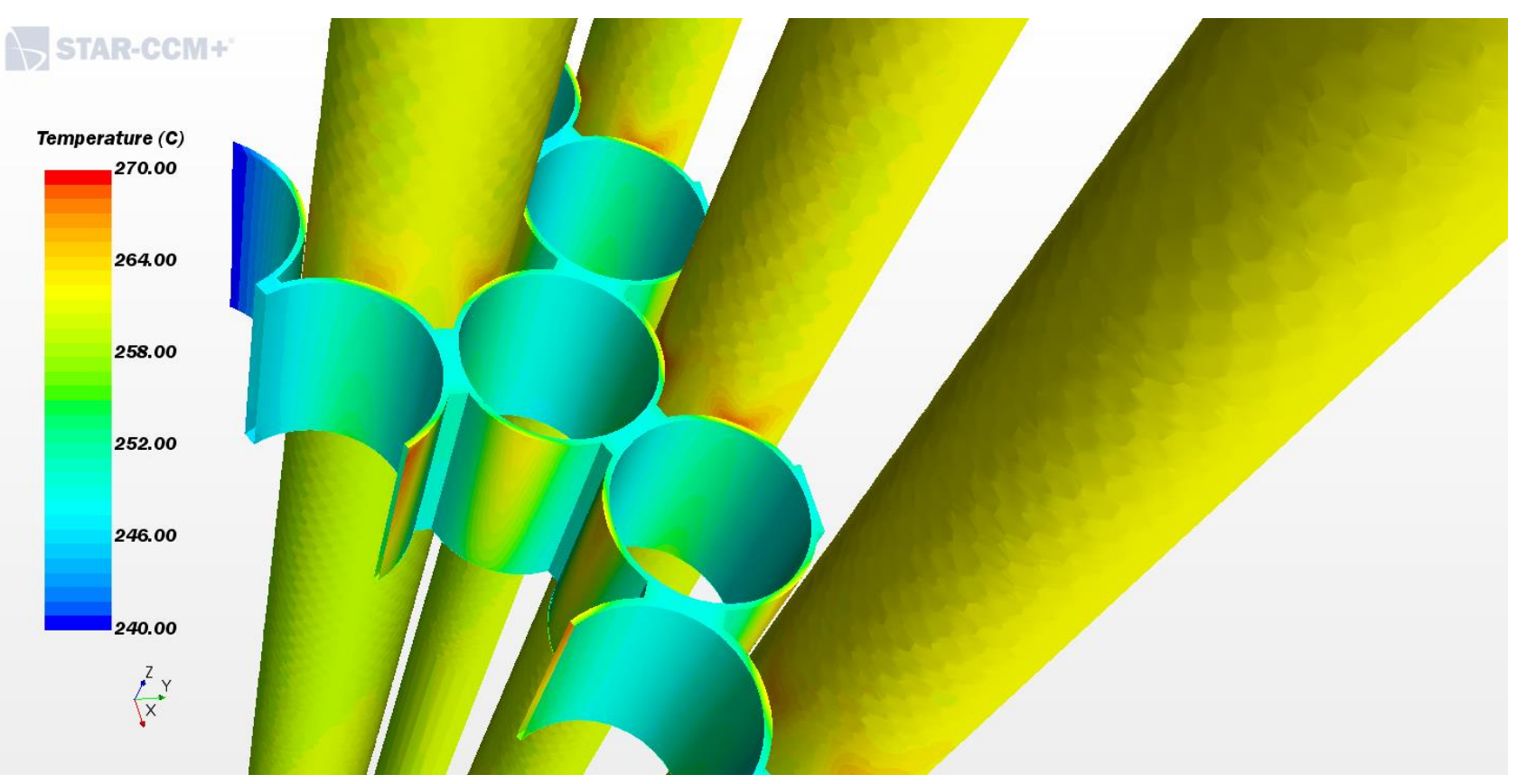

(a) 


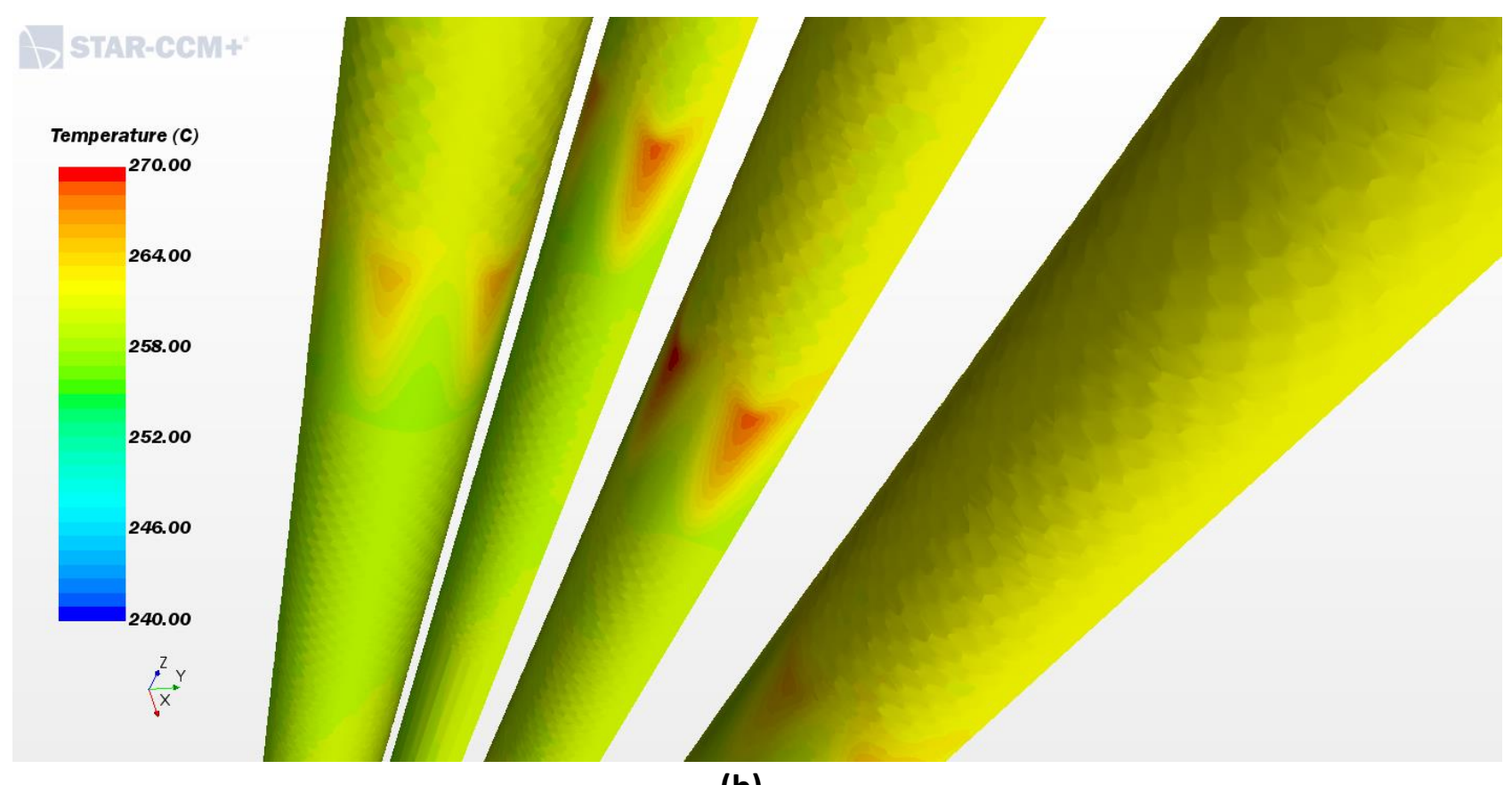

(b)

Figure 9: Pin wall temperature distribution (a) showing and (b) not showing the middle spacer grid

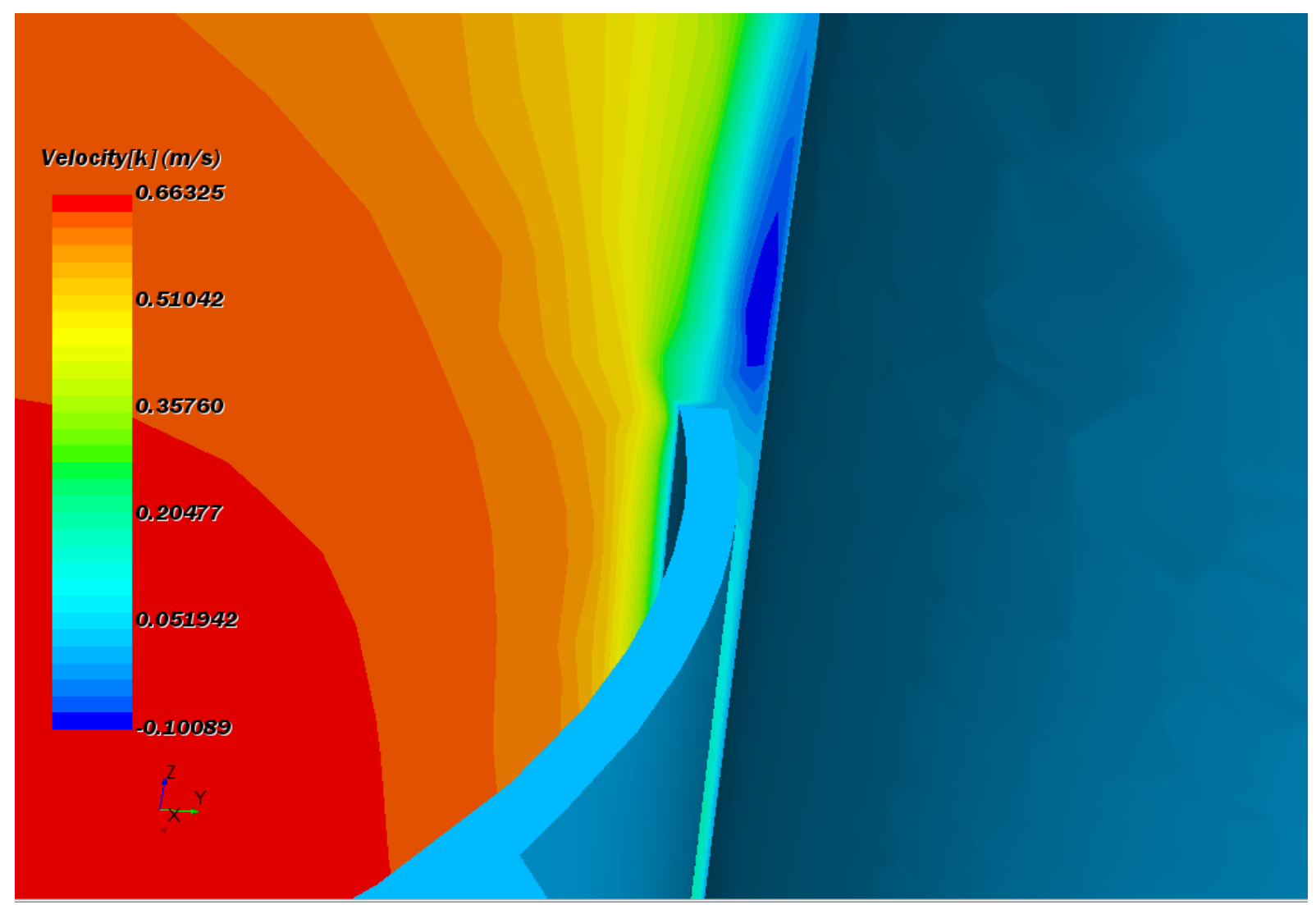

(a) 


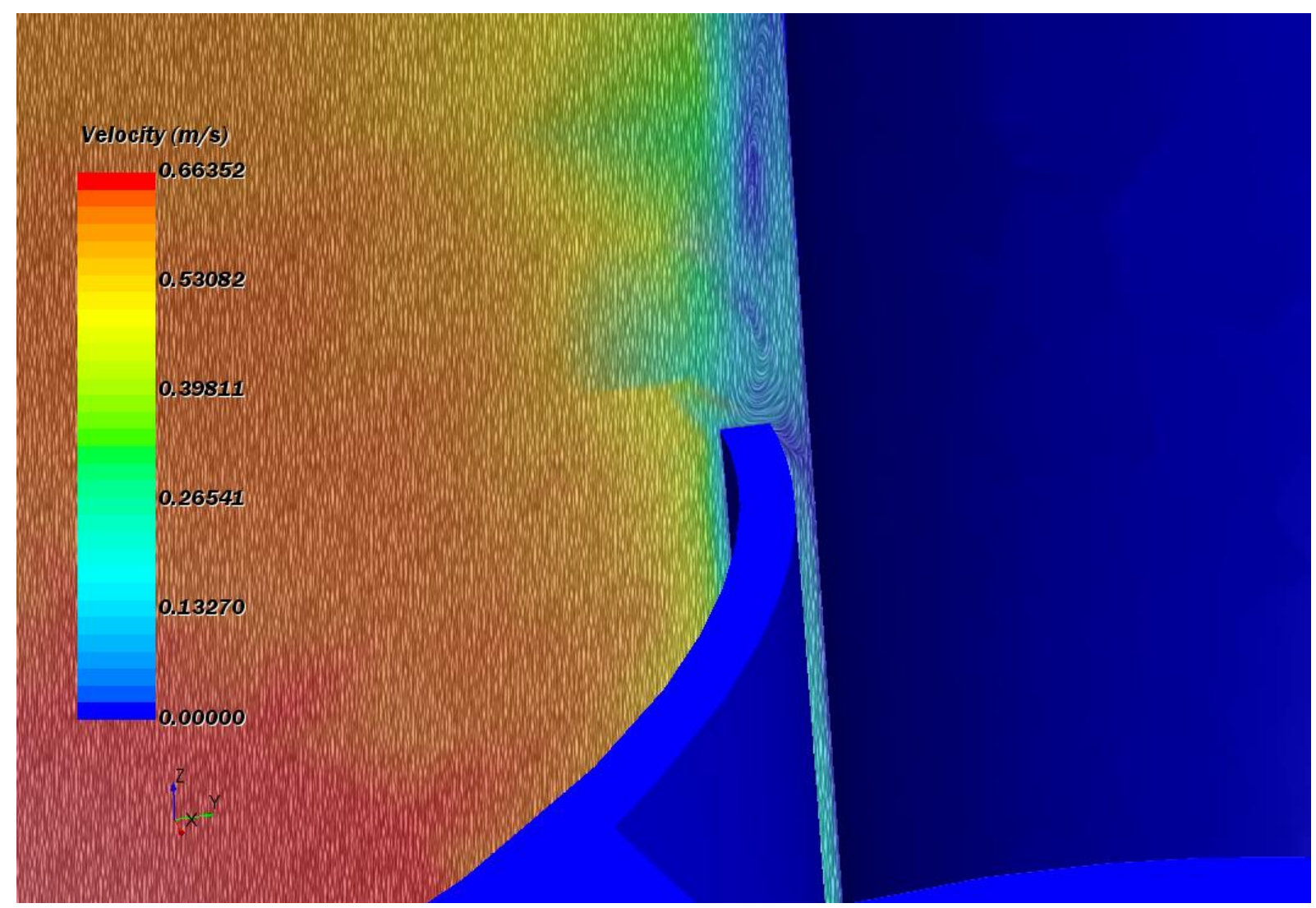

(b)

Figure 10: Detail of the (a) axial velocity and (b) velocity vector distributions in the grid-pin fluid region

\subsection{Transient case}

The presently addressed transient case reproduces a postulated Protected Loss of Flow Accident (PLOFA) consisting in three phases: the initial steady-state condition (before the transient) characterised by high mass flow rate (forced circulation condition) and supplied thermal power values, the postulated accident, consisting in a mass flow rate and thermal power sharp drop which, eventually, reaches a new quasi-steady state (natural circulation condition) characterized by a slow variables stabilization. Firstly, a steady-state calculation reproducing the conditions occurring before the postulated accident was performed; URANS calculation were subsequently performed reproducing the following 1800 seconds of transient for the considered experiment. In particular, the fluid temperature at the FPS outlet section was taken into account, comparing the CFD results with the available experimental data with the aim of assessing the involved heat transfer phenomena occurring between the FPS component and the pool.

A sensitivity analysis considering different thermal boundary conditions for the FPS external walls was performed with the purpose of assessing which condition could better reproduce the FPS energy balance and if simplifying hypotheses would allow obtaining suitable results. In similarity with the results for the steady-state calculations reported in the previous sections, the first simulation of the transient was setup adopting an adiabatic thermal condition. As reported in Figure 11 a this assumption leads to the prediction of temperatures which are significantly lower than the experimental values, suggesting that for transient conditions heat transfer phenomena occurring between the pool and the FPS cannot be neglected. These phenomena are relevant because of the 
large differences in the pool and FPS thermal inertia. In fact, after the supplied thermal power decreases, the temperature of LBE inside the FPS immediately drops; on the contrary, thanks to the greatly higher thermal inertia, the LBE temperature inside the pool downcomer remains almost constant during the first part of the transient. This results in a relevant temperature difference between the fluid inside the FPS and the one in the pool leading to heat transfer phenomena that cannot be neglected in the energy balance of the FPS component.

Consequently, calculations considering an imposed temperature or convective conditions were performed; in particular, a heat transfer coefficient of $2000 \mathrm{~W} /\left(\mathrm{m}^{2} \mathrm{~K}\right)$ was selected since it granted the best results for the starting steady-state condition and it was found as a suitable value in agreement with what obtained in the previous work of Buzzi et al. (2020). In both cases, the external temperature is the one measured in the pool at the beginning of the transient, maintained constant during the calculation. Results obtained imposing these conditions were reported in Figure 11b. It can be noted that, assuming an imposed temperature, CFD overpredicts the experimental data; on the other hands, the convective case $\left(h=2000 \mathrm{~W} / \mathrm{m}^{2} \mathrm{~K}\right)$, in the initial part of the simulation (0-400 seconds), shows results that are in good agreement with experimental ones; nevertheless, CFD predicts a higher outlet temperature in the last part of the simulation. This suggests that, though the thermal inertia of the pool is larger than the one of the fluid flowing inside the FPS, the temperature inside the pool cannot be regarded as constant.

As a consequence, a decreasing pool temperature with respect to time was imposed for the convective boundary condition assuming a linear trend in similarity with the experimental data. The results obtained for this case were reported in Figure 11c. It can be easily noted that experimental measurements are well reproduced by CFD simulation and negligible differences appear. As a consequence, at least for the transient case, no simplifying condition may be assumed, and suitable results can be obtained only imposing boundary conditions as close as possible with the experimental test.

This becomes clear when considering the energy balance for the FPS component represented by the following equation:

$$
\rho \cdot V \cdot c_{v} \cdot \frac{d T}{d t}+\dot{m}_{L B E} \cdot c_{p}\left(T_{\text {out }}-T_{\text {in }}\right)=\dot{Q}_{\text {pins }}+\dot{Q}_{\text {ext }}
$$

with $c_{p} \cong c_{v} \cong 141 \mathrm{~J} /(\mathrm{kgK}), \rho \cong 10168.7 \mathrm{~kg} / \mathrm{m}^{3}$ and $V \cong 7.244 \cdot 10^{-4} \mathrm{~m}^{3}$.

$\dot{Q}_{\text {pins }}$ and $\dot{Q}_{\text {ext }}$ are, respectively, the heat power generated by the pins and the heat power exchanged through the FPS external shroud from the pool towards the FPS itself. Figure 12a reports the trend of the four contributions appearing in the considered balance equation as a function of time and calculated on the basis of the experimental data; in particular, it is worth observing the trends in the initial part of the transient reported in Figure 12b. As the power supplied by the pins drops, the outlet temperature immediately decreases too; as a result of the general temperature decrease inside the FPS, the time derivative of the internal energy becomes negative. In particular, it is important observing that during the initial part of the transient, the heat transferred from the pool towards the FPS reaches a peak of about $18 \mathrm{~kW}$, proving that this contribution cannot be neglected in the total energy balance. Eventually, in Figure 12a, it can be observed that all the considered quantities become constant after about three minutes, meaning that a new quasi-steady state condition have been achieved. 


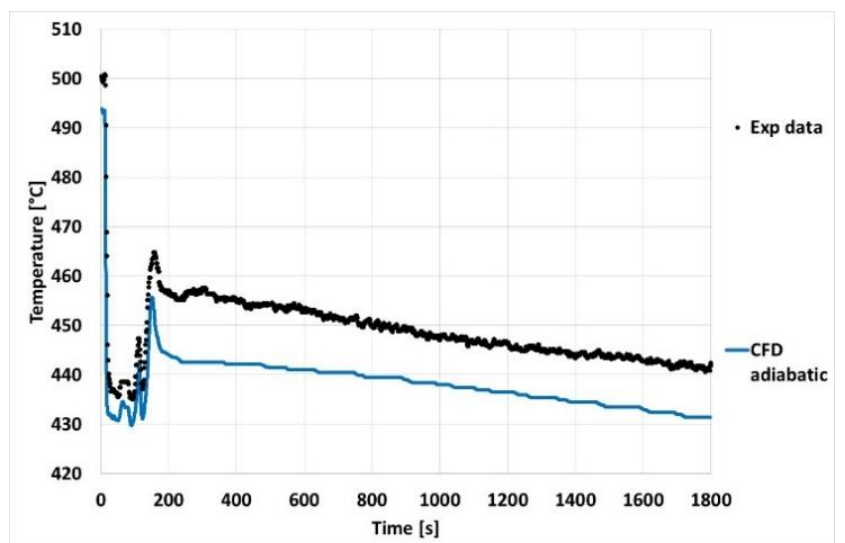

(a)

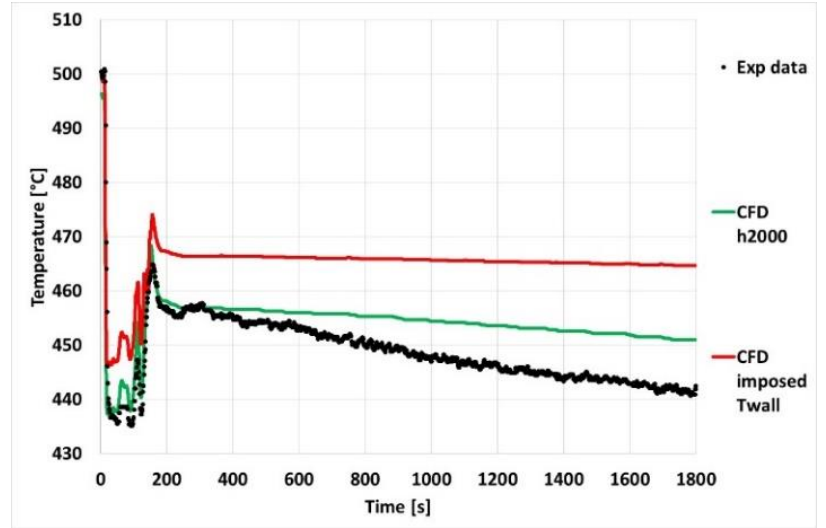

(b)

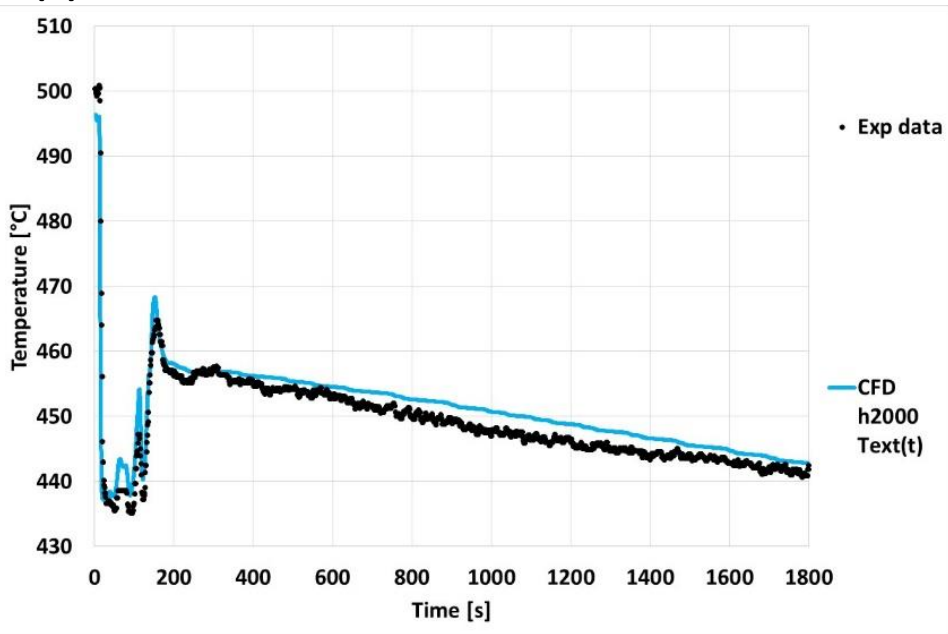

(c)

Figure 11: CFD and experimental comparison of the FPS outlet temperature trend using the (a) adiabatic, (b) $\mathrm{h}=2000 \frac{W}{m^{2} K}$ convective and imposed temperature and (c) $\mathrm{h}=2000 \frac{W}{m^{2} K}$ convective time-dependent thermal boundary conditions

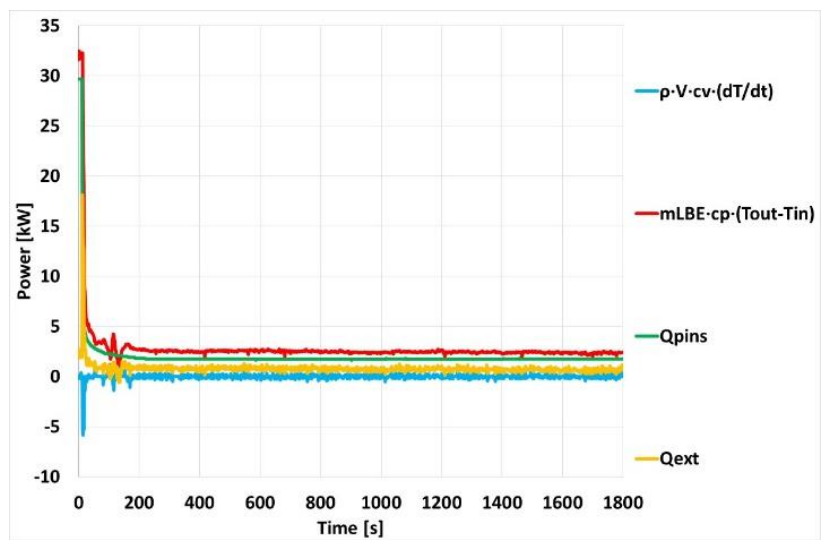

(a)

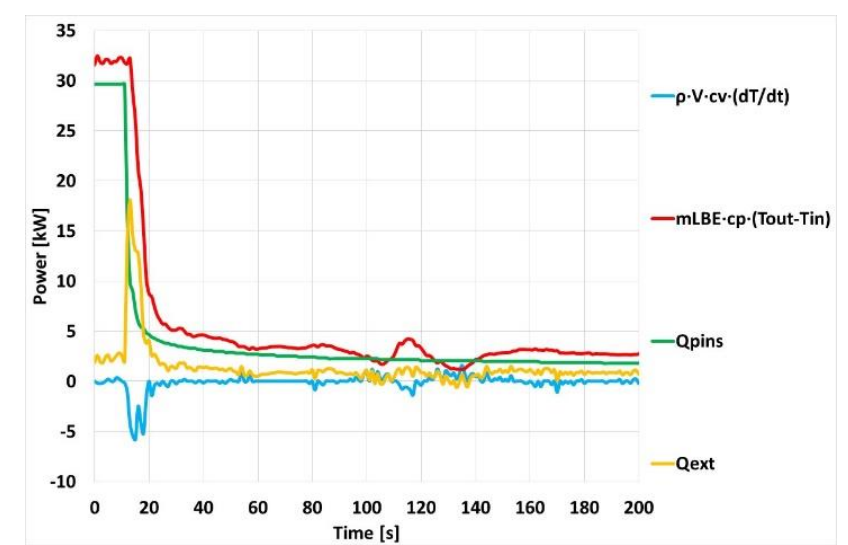

(b)

Figure 12: Evolutions during the transitory of the FPS energy equation terms

\section{Conclusions}


This paper presents a CFD analysis of the fuel pin simulator of the liquid metal pool-type CIRCEHERO facility, built at the ENEA research centre in Brasimone.

Several RANS and URANS simulations were performed adopting the STAR-CCM+ code with the purpose of reproducing both steady and transient experimental tests. The thermo-physical behaviour of the LBE flowing inside the Fuel Pin Simulator (FPS) was thoroughly analysed and the CFD trends were compared with different experimental measurements of the temperature axial distribution.

In order to study the relevance of the heat transfer between the pool and the FPS, a sensitivity analysis of the thermal boundary conditions imposed at the external walls of the FPS for a steadystate case was performed. The analysis pointed out the negligible influence of the external heat transfer on the FPS temperature field and therefore, the adiabatic wall hypothesis was adopted for all the steady-state simulations. For the latter, a good matching between experimental and numerical results was achieved and CFD managed to predict the slight temperature relative peak in correspondence of the spacer grid. This phenomenon was analysed in detail studying the temperature and the velocity fields in these regions; a stagnation zone downstream the spacer grid was observed, which implies an impairment of the general heat transfer capabilities.

The considered transient test reproduce a Protected Loss of Flow Accident (PLOFA): the averaged outlet temperature was monitored for the 1800 seconds transient case comparing CFD and experimental trends. A first attempt was carried out adopting an adiabatic thermal condition at the FPS external walls obtaining a significant discrepancy with experimental measurements; actually, reducing the thermal source power, temperature inside the FPS component immediately decreases, while, due to the high thermal inertia, pool temperature needs longer times to be affected by the source power reduction. Consequently, a high temperature difference and heat transfer between FPS and pool are established and cannot be neglected; for this reason, two simulations with an imposed temperature and a convective thermal boundary conditions were performed. Results obtained adopting the convective condition were in good agreement with experimental ones for the very first part of the transitory, but in the final part an excessive averaged outlet temperature was obtained. This discrepancy is due to the slow pool temperature reduction during the experiment; in order to consider this phenomenon, a time decreasing pool temperature was implemented in the convective simulation obtaining excellent result. In addition, a quantitative analysis of the FPS energy equation terms was carried out showing the relevance of the external heat transfer term.

Further works on liquid metals pool facilities are necessary in order to assist the Generation IV Nuclear Power Plants design and results obtained in this study will be considered in support of futures CFD and system-codes liquid metals thermal-hydraulics analyses.

\section{References}

Abderrahim, H.A., 2011. MYRRHA Technical Description. SCKCEN/593205/42. 
Angelucci, M., Martelli, D., Barone, G., Di Piazza, I., Forgione, N., "STH-CFD Codes Coupled Calculations Applied to HLM Loop and Pool Systems", Science and Technology of Nuclear Installations, 2017a, Article ID 1936894.

Buzzi, F., Pucciarelli, A., Galleni, F., Tarantino, M., Forgione, N., "Analysis of thermal stratification phenomena in the CIRCE-HERO Facility", Annals of Nuclear Energy, Volume 141, 15 June 2020

Chandra, L., Roelofs, F., Houkema, M., Jonker, B., "A stepwise development and validation of a RANS based CFD modelling approach for the hydraulic and thermal-hydraulic analyses of liquid metal flow in a fuel assembly". Nuclear Engineering and Desing 239 (2009) 1988-2003

Chandra, L., Roelofs, F., "CFD analyses of liquid metal flow in sub-channels for Gen IV reactors". Nuclear Engineering and Desing 241 (2011) 4391-4403

Cheng, X., Tak, N., "Investigation on turbulent heat transfer to lead-bismuth eutectic flows in circular tubes for nuclear applications" Nuclear Engineering and Desing 236 (2006) 385-393

Di Piazza et al., "Nacie-UP: an heavy liquid metel loop for mixed convection experiments with instrumented pin bundle" HLMC-2013, 2013.

Forgione, N., Angelucci, M., Ulissi, C., Martelli, D., Barone, G., Ciolini, R., Tarantino, M., “Application of RELAP5/Mod3.3 - Fluent coupling codes to CIRCE-HERO", Journal of Physics: Conference Series. IOP Publishing, 2019. p. 012032.

GIF, 2010. Introduction to Generation IV nuclear energy system and the international forum. URL; http://www.gen-4.org

Gonfiotti, B., Barone, G., Angelucci, M., Martelli, D., Forgione, N., Del Nevo, A., Tarantino, M., "Thernal hydraulic analys of the circe-hero pool-type facility", International Conference on Nuclear Engineering, Proceedings, ICONE Volume 6B, 20182018 26th International Conference on Nuclear Engineering, ICONE 2018; London; United Kingdom; 22 July 2018 through 26 July 2018; Code 141167

Groetzbach, G., "TURBULENCE MODELING ISSUES IN ADS THERMAL AND HYDRAULIC ANALYSES" IAEA Technical Meeting on Theoretical and Experimental Studies of Heavy Liquid Metal Thermal Hydraulics, Karlsruhe, Germany, Oct. 28-31, 2003 
Grishchenko, D., Jeltsov, M., Kööp, K., Karbojian, A., Villanueva, W., "The TALL-3D facility design and commissioning tests for validation of coupled STH and CFD codes". Nuclear Engineering and Desing 290(2015)144-153

Lorusso, P., Pesetti, A., Tarantino, M., Polazzi, G., Sermenghi, V., “CIRCE Experiment report” ENEA report for Project MYRTE, Ref. Cl-I-R-353, 2018.

Lorusso, P., Tarantino, M., Polazzi, G., Sermenghi, V., “CIRCE-HERO PLOFA EXPERIMENT". ENEA report for Project SESAME, 2019.

Martelli, D., Forgione, N., Barone, G., Del Nevo, A., Di Piazza, I., Tarantino, M., “Coupled simulations of natural and forced circulation tests in NACIE facility using relap5 and Ansys fluent codes" 2014 22nd International Conference on Nuclear Engineering, ICONE 2014; Prague; Czech Republic; 7 July 2014 through 11 July 2014; Code 109131.

Martelli, D., Marinari, R., Barone, G., Di Piazza, I., Tarantino, M., "CFD thermo-hydraulic analysis of the CIRCE fuel bundle", Annals of Nuclear Energy, Volume 103, 1 May 2017, Pages 294-305, $2017 a$

Martelli, D., Forgione, N., Barone, G., Di Piazza, I., "Coupled simulations of the NACIE facility using RELAP5 and ANSYS FLUENT codes", Annals of Nuclear Energy, Vol. 101, pp. 408-418, 2017b.

Menter, F.R., "Two-equation eddy-viscosity turbulence modelling for engineering applications". AIAA Journal 32(8) pp. 1598-1605, 1994.

Narcisi, V., Giannetti, F., Tarantino, M., Martelli, D., Caruso, G., "Pool temperature stratification analysis of CIRCE-ICE facility with RELAP5-3D ${ }^{\odot}$ model and comparison with experimental tests", Journal of Physics: Conference Series, Volume 923, Issue 1, 20 November 2017, Article number 01200635th Italian Union of Thermo-Fluid Dynamics Heat Transfer Conference, UIT 2017; Faculty of Engineering, Marche Polytechnic University Ancona; Italy; 26 June 2017 through 28 June 2017; Code 131974

Papukchiev, A., Jeltsov, M., Kööp, K., Kudinov, P., Lerchl, G., “Comparison of different CFD-STH approaches for pre-test analysis of a TALL-3D experiment". Nuclear Engineering and Desing 290(2015)135-14

Pesetti, A., Forgione, N., Narcisi, V., Lorusso, P., Giannetti, F., Tarantino, M., “ENEA CIRCE-HERO test facility: geometry and instrumentation description", ENEA report for Project H2020 SESAME Project WP5.2, Ref. Cl-I-R-343, 2018a. 
Pesetti, A., Lorusso, P., Polazzi, G., Sermenghi, V., Tarantino, M., “CIRCE-HERO test facility: heat losses characterization tests", ENEA report, Ref. CI-I-R-351, 2018b.

Pucciarelli, A., Barone, G., Forgione, N., Galleni, F., Martelli, D., "NACIE-UP post-test simulations by CFD codes". Nulcear Engineering and Design 356 (2020) 110392

Roelofs, F., Gopala, V. R., Jayaraju, S, Shams, A., Komen, E., "Review of fuel assembly and pool thermal hydraulics for fast reactors", Nuclear Engineering and Desing (2013) 1205-1222

Shams, A., Roelofs, F., Baglietto, E., Lardeau, S., Kenjeres, S., "Assessment and calibration of an algebraic turbulent heat flux model for low-Prandtl fluids", International Journal of Heat and Mass Transfer 79 (2014) 589-601

Shams, A., De Santis, A., Roelofs, F., "An overview of the AHFM-NRG formulations for the accurate prediction of turbulent flow and heat transfer in low-Prandtl number flows", Nuclear Engineering and Design 355 (2019) 110342

Siemens, "USER GUIDE STAR-CCM+ Version 13.06.011", 2018.

Tarantino, M., Agostini, P., Benamati, G., Coccoluto, G., Gaggini, P., Labanti, V., Venturi, G., Class, A., Liftin, K., Forgione, N., Moreau, V., "Integral Circulation Experiment: Thermal-hydraulic simulator of a heavy liquid metal reactor", Journal of Nuclear Materials 415r, 433-448, 2011

Toti, A., Vierendeels, J., Belloni, F., "Extension and application on pool-tpe test facility of a system thermal hydraulic/CFD coupling method for transient flow analyses". Nuclear Engineering and Desing 331 (2018) 83-96.

Zwijsen, K., Dovizio, D., Moreau, V., Roelefs, F., "CFD modelling of the CIRCE facility". Nuclear Engineering and Desing 353 (2019) 110277, 2019a

Zwijsen, K., Martelli, D., breijder, P.A., Forgione, N., Roelefs, F., "Multi-scale modelling of the CIRCEHERO facility". Nuclear Engineering and Desing 355 (2019) 110344, 2019b 